\title{
DIFERENÇAS QUE CARACTERIZAM O DRAMA A STREETCAR NAMED DESIRE E SUA TRADUÇÃO UM BONDE CHAMADO DESEJO
}

\author{
DIFFERENCES THAT CHARACTERIZE THE DRAMA A STREETCAR NAMED \\ DESIRE AND ITS TRANSLATION UM BONDE CHAMADO DESEJO
}

Recebido: $27 / 10 / 2021$

Aprovado: 08/12/2021

Publicado: 22/12/2021

DOI: $10.18817 /$ rlj.v5i2.2693

Gustavo Cardoso Silveira ${ }^{1}$

Orcid ID: https://orcid.org/0000-0002-6864-4860

\begin{abstract}
RESUMO: O objetivo deste artigo é a comparação entre o original em língua inglesa do drama $A$ Streetcar Named Desire, de Tennessee Williams, com a tradução em português, Um bonde chamado Desejo, de Vadim Nikitin, a fim de identificar as categorias linguísticas que apresentam diferenças entre as duas versões. Nos anos noventa, o conceito do tradutor subserviente foi substituído por outro, visivelmente manipulador, entendido como um sujeito inserido em um contexto cultural, ideológico, político e psicológico - não podendo ser ignorado ou eliminado. Como resultado dessas imposições, o tradutor é obrigado a fazer escolhas nem sempre fiéis às da língua do texto original, implicando em diferenças na interpretação do texto. A análise tem o apoio da Linguística Sistêmico-Funcional (LSF), uma proposta teórico-metodológica, de Halliday (1994), Halliday; Matthiessen (2004) e seus colaboradores. Como Martin e White (2005, p. 7) explicam, "a LSF é "um modelo multiperspectivo, designado a dar aos analistas lentes complementares para a interpretação da língua em uso". Os resultados da análise mostram a impossibilidade de uma tradução exata e fiel ao original, devido a dificuldades de natureza tanto referentes à subjetividade do tradutor, quanto às características tipológicas das línguas em confronto.
\end{abstract}

Palavras-chave: Tradução. Comparação. Linguística. Literatura. Sistêmico-Funcional.

Abstract: The purpose of this article is to compare the English-language original of Tennessee Williams' drama A Streetcar Named Desire with Vadim Nikitin's Portuguese translation, Um bonde chamado Desejo, to identify the language categories that have differences between the two versions. In the 1990s, the concept of the subservient translator was replaced by another, visibly manipulative, understood as a subject inserted in a cultural, ideological, political, and psychological context - and cannot be ignored or eliminated. As a result of these impositions, the translator is obliged to make choices not always faithful to those of the language of the original text, implying differences in the interpretation of the text. The analysis is supported by Systemic-Functional Linguistics (LSF), a theoretical-methodological proposal by Halliday (1994), Halliday; Matthiessen (2004) and his collaborators. As Martin and White (200, p. 7) explain, "LSF is "a multiperspective model, designed to give analysts complementary lenses for interpreting the language in use." The results of the analysis show the impossibility of an accurate and faithful translation of the original, due to difficulties of nature both related to the subjectivity of the translator, as well as the typological characteristics of the languages in confrontation.

Keywords: Translation. Comparison. Linguistics. Literature. Systemic-Functional.

\section{INTRODUÇÃO}

Os teóricos da tradução não poderiam ir além de uma avaliação subjetiva e normativa dos textos se não se voltarem para a linguística (BELL, 1991). A esse

\footnotetext{
1 Doutorando em Linguística Aplicada e Estudos da Linguagem (PUC-SP); Mestre em Linguística Aplicada e Estudos da Linguagem (PUC-SP); Especialista em Língua Inglesa e Psicopedagogia; Professor de Línguas e Literaturas (português/inglês), Atuando há 18 anos com educação e formação de professores, possui experiência em mentoring e coaching de novos profissionais. Trabalhando com o desenvolvimento de projetos, com a apresentação de workshops e com cursos de formação. Examinador Cambridge ESOL. E-mail: gus.cs@uol.com.br
} 
respeito, Nida (2001, p. 244) refere-se a "estudiosos que têm abordado a questão a partir de pontos de vista das diferenças linguísticas entre os textos de origem e os de destino". Mais recentemente, Ming (2007) recorreu à teoria da Linguística SistêmicoFuncional (LSF) para os estudos a partir de parâmetros funcionais, como a transitividade, a modalidade e a estrutura temática, entre outros. Assim também, Zhang e Huang (2003) recorreram à perspectiva funcional, apoiando-se em características textuais, escolha linguística, além da relação entre língua e seu contexto de realização.

Por outro lado, o importante trabalho de estudiosos da tradução baseado em linguística, como os de: Mona Baker, Roger Bell, Basil Hatim, lan Mason, Kirsten Malmkjaer, Katharina Reiss, Hans Vermeer e Wolfram Wilss, para citar apenas alguns dos mais conhecidos, tem feito muito para romper as fronteiras entre diferentes disciplinas dedicadas à tradução e tirar seus estudos de uma posição de possível confronto (cf. BASSNETT, 2004)).

A propósito, a hipótese do determinismo/relativismo linguísticos de que línguas diferentes influenciam o pensamento de maneiras diferentes existe desde o início da filosofia, segundo Slobin (1980), e pode interessar ao estudo da tradução. Começamos a pensar nessa hipótese quando comparamos línguas e descobrimos quão distintas podem ser as categorias das experiências incorporadas.

Relacionada a esses fatos, a conferência interdisciplinar pioneira sobre a questão dos universais linguísticos, organizada em 1961, gerou bastante informação a esse respeito, e veio a revelar padrões comuns surpreendentes, dando início à noção de tipologia linguística. A consideração desse fator é essencial na tradução, já envolvem: tendências humanas a pensar e imaginar de certa maneira; exigências de realização impostas por um código que se enfraquece rapidamente e é temporariamente ordenado (seja fala auditiva ou sinal visual); natureza e metas da interação humana.

O objetivo deste artigo é a comparação entre o original em língua inglesa do drama $A$ Streetcar Named Desire, de Tennessee Williams, com a respectiva tradução em português, Um bonde chamado Desejo, de Vadim Nikitin, a fim de identificar as categorias linguísticas que apresentam diferenças entre as duas versões com base nas escolhas lexicogramaticais feitas pelos referidos autores.

Para tanto, esta pesquisa busca responder às seguintes perguntas: (a) De que natureza são as modificações decorrentes das escolhas lexicogramaticais na 
tradução de $A$ Streetcar Named Desire para a língua inglesa? (b) Quais as consequências dessas escolhas? (c) Qual é a contribuição da Linguística SistêmicoFuncional nesse processo?

O presente estudo tem o apoio da Linguística Sistêmico-Funcional (LSF) (HALLIDAY, 1994, HALIDAY; MATTHIESSEN, 2004), uma proposta teóricometodológica, que abarca as seguintes premissas: o uso da língua é funcional; sua função é construir significados; os significados são influenciados pelo contexto social e cultural em que são intercambiados; o processo de uso da língua é um processo semiótico, um processo de fazer significado por meio de escolhas.

\section{Fundamentação teórica}

São apresentadas a seguir as teorias que embasam a análise comparativa entre o original do drama A Streetcar Named Desire e sua tradução para o português: estudos da tradução, determinismo linguístico, tipologia linguística e a Linguística Sistêmico-Funcional.

\subsection{A tradução}

As teorias da linguagem que emergem da tradição intelectual do Ocidente, alicerçadas no logocentrismo e na crença que Jacques Derrida chamada de "significado transcendental", têm considerado o texto de partida como um objeto definido, congelado, receptáculo de significados estáveis, geralmente identificados com as intenções de seu autor (ARROJO, 1993, p. 16).

Porém toda tradução, por mais simples e breve que seja, trai sua procedência, revela as opções, as circunstâncias, o tempo e a história de seu realizador, ou seja, se revela produto de uma perspectiva, de um sujeito interpretante e, não, meramente, de uma compreensão neutra e desinteressada ou de um resgate correto ou incorreto dos significados supostamente estáveis do texto de partida. Portanto, "nenhuma tradução será [...] "neutra" ou "literal"; será, sempre e inescapavelmente, uma leitura" (ARROJO, 2003, p.68).

Nos anos 1990, a figura do tradutor subserviente foi substituída por uma visivelmente manipuladora, o artista criativo mediador de línguas e culturas (BASSNETT, 2004). Mas o que mudou? Bohunovsky (2001, p. 54) postula a mudança 
no tradutor, sendo ele entendido "como um sujeito inserido num certo contexto cultural, ideológico, político e psicológico - fatores que não podem ser ignorados ou eliminados na elaboração de uma tradução", tornando-se "visível". Dessa forma, deixou-se de esperar dele uma tarefa, como diz Arrojo (1993), impossível: alguém não apenas invisível e inconspícuo, mas colocando-se na pele, no lugar e no tempo do autor que traduz, sem deixar de ser ele mesmo e sem violentar a sintaxe e a fluidez de sua língua, de seu tempo.

Se pensarmos a tradução do ponto de vista da Linguística Sistêmico-Funcional (LSF), veremos as escolhas lexicogramaticais como importantes, principalmente se olharmos para elas como alternativas para aquelas que poderiam ter sido feitas e os efeitos de sentido criados. Não é outra a situação no campo da literatura, pois, diante de um texto literário, os tradutores fazem seleções não neutras, pois refletem a influência, a ideologia, a subjetividade e a visão individual. O determinismo linguístico, a seguir, pode explicar parte dessa influência.

\subsection{Relatividade e Determinismo Linguísticos}

A Relatividade e o Determinismo linguísticos vieram a ter o nome de hipótese whorfiana, em homenagem a Benjamin Lee Whorf, que devotou grande atenção ao problema (WHORF, 1956). Comecemos com uma afirmação feita por Edward Sapir, o grande linguista, professor de Whorf:

\footnotetext{
Os seres humanos não vivem isolados no mundo objetivo, nem no mundo da atividade social como ordinariamente se entende, mas estão muito a mercê da língua que se tornou o meio de expressão de sua sociedade. O fato de que o "mundo real" é, em larga extensão, inconscientemente construído sobre os hábitos linguísticos do grupo (MANDELBAUM, 1958, p. 162).
}

$E$, se, nesse contexto, compararmos diferentes língua, veremos diferenças, tanto nas categorias expressas quanto nos meios linguísticos especiais empregados para a sua representação. Essas diferenças vão além do fato conhecido da impossibilidade de uma tradução literal da maioria das palavras posto que nem sempre há um equivalente perfeito.

Examinemos as questões mencionadas acima de maneira mais detalhada. Inicialmente, pode-se perguntar o motivo de os indivíduos falarem de relatividade linguística. Podemos começar com o nível lexical: (a) uma das línguas tem palavras para as quais não há, de forma alguma, equivalentes na outra língua (ex.: "pinga"; 
"tatame"); (b) as línguas também diferem no fornecimento de hiperônimos para designar várias categorias. Ex.: "nut" (inglês) não tem tradução para o português; e (c) as línguas diferem no modo como seccionam os vários campos semânticos. As línguas diferem tanto no número de termos para cor, quanto no modo como dividem o continuum do espectro solar (SLOBIN, 1980).

Quanto ao nível gramatical, há aqui uma variedade de classificações obrigatórias incorporadas à gramática, às quais geralmente não prestamos atenção (SLOBIN, 1980). Tem-se generalizado a noção de que as categorias gramaticais de uma língua nos levam, sem que o percebamos, a prestar atenção nos diferentes atributos das situações. Assim, no japonês não há como traduzir "Eu tenho dor de cabeça", que corresponde a "A cabeça dói", pois para eles "dor de cabeça" não é uma propriedade de "eu". Exemplos como este impedem uma tradução inteiramente fiel ao original. Esse tipo de questão pode ser esclarecida, em parte, pela noção de tipologia linguística, que apresentamos a seguir.

\subsection{Tipologia das línguas}

O ensino de inglês, como língua estrangeira, tem se mostrado uma área em franco desenvolvimento e tem crescido bastante no Brasil nos últimos anos. $O$ processo de ensino-aprendizagem exige o conhecimento não só das regras gramaticais envolvidas no processo tradutório, mas também do contexto sociocultural que cerca o uso dessas línguas.

Ilustram a questão, exemplos como os seguintes. As vendas do Corsa da GM não decolaram quando o carro foi oferecido na Espanha com o nome de NOVA (No $v a=$ não vá). Já, mais cuidadosa, a Mitsubishi, que vende o modelo 4x4 no Brasil e na Grã-Bretanha com o nome de Pajero, rebatizou-o, em países de língua espanhola como Montana, pois "pajero" significa "masturbar", nesses lugares.

A propósito, o chinês, segundo Ming (2007), constrói significados com menos conjunções do que o inglês, não tendo abundância de orações subordinadas, pois organiza as orações uma após outra sem o uso de conectivos; já o inglês constrói significados por meio de construções subordinadas, lançando mão de conectivos para estabelecer as relações lógicas entre orações.

Fillmore (1988) ampliou nossa visão de semântica, colocando o significado das palavras no enquadre cognitivo. Em sua proposta, Fillmore e Atkins (1992, p. 78) 
propuseram - e demonstraram - que "o significado das palavras só pode ser entendido com referência ao contexto da estrutura da experiência, crenças ou práticas, constituindo uma espécie de pré-requisito conceitual para o entendimento do significado".

Nesse contexto, Slobin (1996) está interessado na questão da tipologia dos padrões lexicais. O contraste tipológico em questão fica claramente demonstrado na comparação do inglês com o espanhol. Essas línguas representam os polos opostos da dicotomia tipológica, que Leonard Talmy $(1985,1991)$ caracterizou como enquadre-satélite versus enquadre-verbo. Consideremos o exemplo prototípico de Talmy sobre a saída de um homem montando seu cavalo, há, em inglês, o satélite do verbo ride, out, expressando a formação nuclear do movimento, enquanto em espanhol, é o verbo por si, salir, que expressa essa informação:

(1) He rode out of the garden X El salió del jardin montando a caballo.

Quadro 1 - Enquadre de Satélite e Enquadre de Verbo

\begin{tabular}{|c|c|c|c|}
\hline \multicolumn{2}{|c|}{ inglês } & \multicolumn{2}{|c|}{ espanhol } \\
\hline rode & out & salió & montando a caballo \\
\cline { 1 - 1 } \cline { 4 - 5 } mov + modo & fora & mov + fora & modo \\
\hline
\end{tabular}

Fonte: adaptado de Talmy, 1991

Notemos que a informação sobre o modo do movimento não é expressa pelo verbo em inglês, mas pelo adjunto adverbial (montando a caballo). Assim, o inglês possui muitos verbos de movimento que expressam o modo, mas não a direção (walk, run, crawl, fly, etc.), combináveis com uma coleção de satélites (in, up to, across, etc.). Já o espanhol prefere verbos inerentemente direcionais (entrar, bajar, subir etc.), com uso mais restrito de movimento não-direcionais e alguns de modo. Talmy (1991, p. 486) propõe que a dicotomia tipológica é universal, dividindo as línguas nas que expressam o "esquema nuclear" (no caso, movimento) por meio de verbos ou satélites.

As línguas que mapeiam o esquema nuclear no verbo são consideradas como tendo um enquadre-de-verbo (espanhol, português e demais línguas românicas, semíticas, japonês). Por outro lado, as que mapeiam o esquema nuclear no satélite serão consideradas como enquadre-de-satélite (o inglês e a maioria das indoeuropeias). Os exemplos (2) e (3) mostram as consequências dessas diferenças tipológica, o que faz, em alguns casos a eliminação $(\varnothing)$ de elementos da oração: 
(2) Gradually he worked his way up to the foot of the bluffs.

Poco a poco, fue acercándose (Ø), hasta el pie de los riscos. [omite "movimento para cima"]

(3) Mrs Tranter rustled forward, effusive and kind. [rustle = sair farfalhando a saia]

(a) Mrs Tranter se adelantó (Ø), efusiva y amable. [ou omite "farfalhar"]

(b) Salió del cuarto, acompañada del susurro siseante de sus ropas. [ou traduz]

\subsection{Linguística Sistêmico-Funcional}

A Linguística Sistêmico-Funcional (LSF) é uma proposta teórico-metodológica de Halliday (1994) e seus colaboradores. Para a LSF, a língua está estruturada para construir três tipos de significados - ou metafunções - simultâneos: ideacional, interpessoal e textual. A metafunção ideacional representa os eventos das orações por meio do sistema da transitividade, que abrange seis processos: material (ator faz algo que atinge a meta); mental (um fenômeno ocorre na mente do experienciador); relacional (há um portador de qualidade); verbal (dizente produz verbiagem); comportamental (um estado psicológico do comportante desencadeia uma ação material ${ }^{2}$, o comportamento); e existencial (existência de uma entidade, o existente).

A metafunção interpessoal abrange $\operatorname{mood}^{\beta}$ e resíduo. $O$ mood envolve: sujeito e finito; o resíduo envolve: predicador, complemento e adjunto (circunstancial ou modal). O mood estabelece relações entre papéis de falante e de ouvinte e inclui a modalidade, envolvendo verbos modais (ex., precisar, poder, querer), adjuntos modais (ex., talvez, certamente) e o tempo verbal.

A metafunção textual constrói os significados ideacionais e interpessoais, para que a informação possa ser compartilhada pelo falante e seu interlocutor, abrangendo: tema - aquilo de que trata a oração - e rema - o resto da mensagem, o desenvolvimento do que foi apresentado (HALLIDAY, 1994).

Finalmente, a metafunção interpessoal divide a oração em: mood + resíduo, em que mood abriga o sujeito e finito (tempo e modalidade). Hoje, essa metafunção conta com a noção de avaliatividade (MARTIN, 2000), rótulo para uma coleção de recursos semânticos, que serve para negociar a ATITUDE referente a afeto (emoções), a julgamento (ético) e à apreciação (estética), incluindo recursos graduáveis (para + ou para - ) para a avaliação de pessoas, lugar e coisas de nossa

\footnotetext{
2 Portanto, independente da vontade do indivíduo.

${ }^{3}$ Mood tem sido traduzido por Modo (com inicial maiúscula). Decidimos manter o termo do original inglês, para evitar confusão com Modo, variável de Registro (contexto situacional).
} 
experiência, e, finalmente, o engajamento, que pode ou não incluir o interlocutor na nossa expressão da avaliatividade, ou seja: heteroglossia e monoglossia, respectivamente.

Recentes publicações mostram que o quadro teórico da LSF pode ser aplicável ao campo dos estudos da tradução, como mostram, por exemplo, alguns tradutores chineses (HUANG, 2006; LI, 2007). Zhang e Huang (2003) expõem a perspectiva funcional para estudos de tradução a partir de vários aspectos: características textuais, contexto e escolha linguística, relação entre significado e sua realização.

$\mathrm{Na}$ década de 1960, durante o boom das teorias linguísticas estritamente científicas, linguistas falantes de inglês também desenvolveram abordagens teóricas da tradução. Na Inglaterra, Catford (1965) aplicou a gramática sistêmica de Halliday à teoria da tradução, categorizando de modo positivo as alterações nas traduções que incidem em: níveis, estruturas, classes de palavras, unidades e sistema.

\subsubsection{A metafunção ideacional e a tradução}

As diferenças entre as línguas em termos da relação lógico-semântica podem ser reveladas por meio de teorias da função lógica, possibilitada pela LSF, o que é benéfico para analisar a distinção inerente entre língua fonte e língua meta, a partir da dimensão da relação oracional.

A tradução pode afetar a informação contida no texto original das seguintes maneiras: (a) mudando o significado semântico das escolhas lexicogramaticais feitas no original, envolvendo: (a) mudança de significado (cf, "open on" x "abertos, mostrando"); (b) ausência no inglês (cf. $\varnothing$ x "vozes") e (c) ausência na tradução (cf. “above" x Ø).

\subsubsection{A metafunção interpessoal e a tradução}

A metafunção interpessoal diz respeito à interação entre 0 falante e o destinatário, o que se manifesta principalmente no nível da oração referentes à modalidade (obrigação, desejabilidade, probabilidade e frequência (HALLIDAY, 1994), e à avaliação (ou avaliatividade) (cf. MARTIN, 2000). No entanto, a organização do sistema de moode as realizações das várias opções, diferem de uma língua para outra. Por exemplo, o grau da categoria gramatical correspondente aos 
comandos é variável: pode haver ou não uma forma distinta do imperativo, e, geralmente, há muitas outras realizações possíveis.

No curso da tradução interlinguística, é vital manter a correspondência dos significados da modalidade e da avaliatividade entre as duas línguas. Para atingir este objetivo, o tradutor deve estar familiarizado com as características dos referidos sistemas realizados no original e na tradução, respectivamente.

\subsubsection{A metafunção textual e a tradução}

No contexto da metafunção textual, Gouveia e Barbara (2004) suscitam argumentos que podem ser úteis para entender as diferenças entre traduções. Tanto o inglês quanto o português apresentam padrão sintático SVO (sujeito, verbo, objeto); no entanto, o português, assim como o espanhol e o italiano, é considerado línguas pro-drop, ou seja, permitem a elisão do sujeito e o posicionamento do predicador em primeiro lugar na oração, o que não acontece no inglês. A questão aqui tratada tanto pode ser considerada do ponto de vista da tipologia linguística, vista acima, quanto da metafunção textual.

O fato de uma língua ser pro-drop, como, por exemplo, o português, acarreta algumas consequências: (1) não há pronomes expletivos como o inglês (it), por exemplo (1); (2) existe a possibilidade de posicionar o sujeito depois do verbo (2); e (3) aparentemente a característica pro-drop parece estar relacionada à rica morfologia verbal, em termos de pessoa e número, o que quer dizer que a ocorrência de sujeitos pronominais, em português, pode ser redundante, se se considerar que, no tempo verbal, informações sobre as pessoas envolvidas ou a identidade do participante esteja codificada no finito:

(1) Chove. (It is raining.)

(2) Apareceu um rato no meu escritório. (It apeared a mouse in my office.)

Por sua vez, Figueiredo (2006) mostra que mudanças temáticas, em especial, interferem na interpretação da mensagem. Nesse contexto, Ninomiya (2012) tratando da questão tema e rema - demonstrou que, mesmo tendo em vista a impossibilidade de uma tradução "ao pé da letra", muitas das diferenças que acabam interferindo na interpretação do texto traduzido em relação ao original podem ocorrer devido ao desconhecimento dessas questões linguísticas. No caso, o original japonês 
trata do início de romance entre dois adolescentes, fazendo com que ora o rapaz ora a moça sejam o tema da oração, aproximando-se sutilmente do par. Já na tradução para a língua portuguesa, por questão da diferença tipológica, essa alternância não foi respeitada, já que os elementos que podem figurar como Tema diferem de uma língua para outra.

\section{METODOLOGIA}

Trata-se de um estudo de caso, uma pesquisa que examina uma unidade, segundo Holloway (1997), cujos limites são esclarecidos em termos de resposta a perguntas feitas, de fontes de dados usadas, e do contexto envolvido. A pesquisa tem o apoio da Linguística Sistêmico-Funcional, uma proposta teórico-metodológica de Halliday (1994).

\subsection{Dados}

O drama A Streetcar Named Desire (ou Um bonde chamado Desejo), de Tennessee Williams é, segundo dados apresentada por Roudané (2009, p. 45), “a primeira peça a ganhar as três maiores premiações, o Pulitzer Prize, o New York Drama Critics' Awards e o Donaldson Award"4. A primeira montagem da peça, dirigida por Elia Kazan, estreou na Broadway em 03 de dezembro de 1947, tendo 855 apresentações até 17 de dezembro de 1949. O texto original de A Streetcar Named Desire, de Tennessee Williams, é da coleção Penguin Modern Classics, edição de 2004, publicado pela editora Penguin UK. Um bonde chamado Desejo foi traduzido por Vadim Nikitin, integrando a coleção Grandes Dramaturgos, V.1, 2004. A seguir, apresento um resumo de $A$ Streetcar Named Desire ou Um bonde chamado Desejo.

Blanche DuBois, uma professora de Laurel, Mississipi, chega em Nova Orleans para ficar por um tempo indeterminado com sua irmã, Stella Kowalski, informando-a que perdeu as propriedades da família. Stella aceita a estadia sob a condição de que ela não incomode seu marido, Stanley, pessoa dura e com hábitos grosseiros, diferente dos sujeitos refinados com as quais Blanche está acostumada a conviver. Um dia, ao retornarem ao apartamento, Blanche é a presentada a Mitch, um solitário em busca de uma esposa, por quem ela se sente atraída. Mitch, então, deixa o jogo de pôquer para conversar, o que enfurece Stanley, fazendo-o agredir Stella. Ao notar

\footnotetext{
4 "[...] became the first play ever to win all three major awards, the Pulitzer Prize, the New York Drama Critics' Award, and the Donaldson Award". (ROUDANÉ, 2009, p. 45, tradução nossa)
} 
que Mitch está interessado em Blanche, Stanley tenta acabar com o relacionamento dos dois como uma forma de se vingar da cunhada, que o tem destratado. Para forçar sua esposa a deixar a amizade com a irmã, ele acaba descobrindo fatos desastrosos contra Blanche: ela não tinha boa fama em Laurel e não está de licença da escola, mas, sim, fora demitida por má conduta sexual, motivo que a fizera deixar a cidade natal.

\subsubsection{Estrutura da peça}

A peça Um bonde chamado Desejo divide-se em 11 cenas. As quebras temporais presentes na peça estão nas cenas 4 e 6, marcando a divisão sazonal, ou seja, as cenas de 1 a 4 apresentam dois dias consecutivos do início de maio; as cenas 5 e 6 tratam de uma noite de agosto; as cenas de 7 a 10 do dia do aniversário de Blanche (15 de setembro); e a cena 11 algumas semanas após seu aniversário, podendo-se inferir outubro. Para o presente artigo, será analisada a cena 11, tendo como recorte os diálogos de 1-5.

\subsection{Procedimentos de Análise}

Para responder às perguntas de pesquisa: (a) De que natureza são as modificações decorrentes das escolhas lexicogramaticais na tradução de $A$ Streetcar Named Desire para a língua inglesa? (b) Quais as consequências dessas escolhas? (c) Qual é a contribuição da Linguística Sistêmico-Funcional nesse processo? foram seguidos os procedimentos abaixo:

(a) Os textos - o original e a tradução - foram colocados lado a lado, em duas colunas, separadas por uma coluna do meio em que se identifica a causa da diferença.

(b) A diferença entre as duas versões foi negritada e colorida de vermelho como mostra o Quadro 2.

(c) Segue-se a Interpretação da causa da diferença, em que os achados foram discutidos tendo como pano de fundo as teorias de apoio.

\section{Quadro 2 - Marcação das diferenças}

\begin{tabular}{|c|c|c|}
\hline $\begin{array}{r}\text { The portières are partly open } \\
\text { on } \\
\text { the poker players - } \\
\text { Stanley, Steve, Mitch }\end{array}$ & MS & $\begin{array}{l}\text { Os reposteiros estão parcialmente abertos, } \\
\text { mostrando } \\
\text { os jogadores } \\
\text { de pôquer - Stanley, Steve, Mitch }\end{array}$ \\
\hline
\end{tabular}


Interpretação: "open on" X "mostrando", enquanto no inglês os reposteiros abrem-se "sobre" os jogadores, a tradução diz que os reposteiros "mostram" os jogadores, afetando a metafunção ideacional.

\section{ANÁLISE E SUA INTERPRETAÇÃO}

A análise comparativa entre $A$ Streetcar Named Desire e Um bonde chamado Desejo busca, a partir das teorias colocadas ao longo do artigo, indicar as diferenças entre as duas versões. Essas diferenças giraram em torno das seguintes causas, conforme o Quadro 3, codificados na análise da seguinte forma:

\section{Quadro 3 - Códigos utilizados para análise}

\begin{tabular}{|l|}
\hline Código de análise \\
\hline$M S=$ mudança semântica \\
$M S($ aval) = mudança na avaliatividade \\
+ AS = mais informação no original \\
AS+ = mais informação na tradução \\
-AS/AS- = menos informação no original e na tradução \\
$\varnothing=$ omissão de informação \\
EI = expressão idiomática \\
TEMA = diferença
\end{tabular}

NOTA: Devido à limitação de espaço, serão analisados os diálogos de 1 a 5 , mas os resultados discutidos referem-se a todos os capítulos analisados.

[1] It is some weeks later. STELLA is packing BLANCHE's things. Sounds of water can be heard running in the bathroom. The portières are partly open

on

the poker players - Stanley, Steve, Mitch and Pablo - who sit around the table in the kitchen.
[1] Algumas semanas depois. Stella está fazendo as malas de Blanche.

Pode-se ouvir o som de água correndo no banheiro. Os reposteiros estão parcialmente abertos,

MS mostrando os jogadores de pôquer Stanley, Steve, Mitch e Pablo - que estão sentados em volta da mesa da cozinha.

Interpretação: Há 2 ocorrências de MS (mudança semântica):

(a) "packing things" $X$ "fazendo as malas", em que a diferença afeta a metafunção ideacional (informação); e

(b) "open on" X "mostrando", enquanto no inglês os reposteiros abrem-se "sobre" os jogadores, a tradução diz que os reposteiros "mostram" os jogadores, afetando a metafunção ideacional. 
[5] PABLO: I am cursing your goddam luck. STANLEY [prodigiously elated]:

You know what luck is? Luck is believing you're lucky.
[5] PABLO: Eu estou amaldiçoando a sua maldita sorte.

STANLEY

[monstruosamente

exultante]:

Sabe o que é sorte? Sorte é acreditar que tem sorte

Interpretação: Note-se que "prodigiously" foi traduzido por "monstruosamente", mesmo tendo à disposição o advérbio correspondente "prodigiosamente", Em termos da avaliatividade, a tradução optou em aumentar a avaliatividade de afeto quanto à graduação de força (seria uma característica latina?).

Take

at Salerno. I believed I was lucky.

(-AS/AS-)

\section{Por exemplo,}

em Salerno. Eu acreditei que tinha sorte

Interpretação: A expressão por extenso em inglês seria "Take for example" e em português, "Tome por exemplo", ou seja. em termos da metafunção ideacional foram omitidas as informações "example" em inglês e "tome", na tradução, facilmente recuperáveis nos dois casos.

\begin{tabular}{|c|c|c|}
\hline $\begin{array}{r}\text { I figured } \\
\text { that } 4 \text { out of } 5 \\
\text { would not } \\
\text { come through } \\
\text { but I would... and I did. }\end{array}$ & $\begin{array}{l}\text { MS } \\
\text { MS }\end{array}$ & $\begin{array}{l}\text { mentalizei } \\
\text { que, de cada cinco, quatro } \\
\text { iam } \\
\text { morrer } \\
\text { e eu não... e deu certo... }\end{array}$ \\
\hline
\end{tabular}

Interpretação: "figure ouf" (descobri) x "mentalizei" (pensei), ambos classificados pela transitividade como processos mentais, mostram pequena diferença de significado: "descobrir" (algo fez surgir na mente) e "mentalizei" (eu fiz surgir na mente).

Entre "but I would... and I did" e "e eu não... e deu certo...", alguns termos foram omitidos, como acontece em diálogos, mas que podem ser recuperáveis com a ajuda do contexto da interlocução.

I put that down as a rule. To hold front position in this rat-race you've got to believe
TEMA Isso para mim é lei.

Nessa corrida de ratos, para ficar em primeiro lugar você tem que acreditar 
Interpretação: "I put that down as a rule" $\mathrm{x}$ "isso para mim é lei' diferem em termos de mood (sujeito + finito) (finito entendido como tempo verbal + modalidade). No caso, o sujeito em inglês é "l", tema da oração, enquanto que na tradução o sujeito é "isso", o tema. A questão é importante, na medida em que o tema influi na interpretação do texto (FIGUEREDO, 2006).

\section{DISCUSSÃO DOS RESULTADOS}

Ao longo do capítulo podemos perceber que há incidências mais evidentes no processo de escolhas do tradutor, sendo um indicativo da presença da voz de um outro ao longo dos diálogos. Os resultados obtidos na análise podem ser observados na Figura 1:

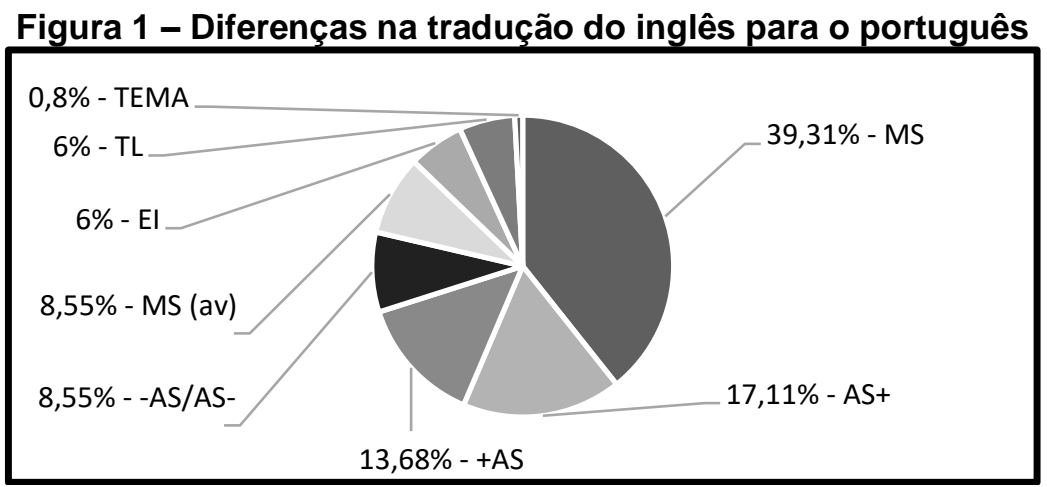

O Quadro 4 retoma os resultados da Figura 1, apresentando o número de incidências de cada uma das ocorrências, elas podem ser vistas não apenas dentro de seu valor percentual, mas também em quantidade de referências para se compreender as escolhas feitas ao longo do texto:

Quadro 4-Comparação entre o original inglês e a tradução em português

\begin{tabular}{|c|c|}
\hline TIPOS DE OCORRÊNCIA & INCIDÊNCIA \\
\hline Mudança Semântica (MS) & $39,31 \%(46)$ \\
\hline Mais informação na tradução (AS+) & $17,11 \%(20)$ \\
\hline Mais informação no original (+AS) & $13,68 \%(16)$ \\
\hline Menos informação no original e na tradução (-AS/AS-) & $8,55 \%(10)$ \\
\hline Mudança na avaliatividade (MS (av) & $8,55 \%(10)$ \\
\hline Expressão idiomática (EI) & $6,0 \%(7)$ \\
\hline Tipologia da língua (TL) & $6,0 \%(7)$ \\
\hline Tema (TEMA) & $0,8 \%(1)$ \\
\hline
\end{tabular}




\section{DISCUSSÃO GERAL DOS RESULTADOS}

Os resultados da análise mostram que uma tradução exata e fiel ao original não é possível e não depende somente da subjetividade do tradutor, pois a língua, em si, apresenta características que levam a modificações necessárias frente ao texto de partida e o texto de chegada. Dessa forma, os dados apresentam categorias que se fazem presentes no processo de. Nida (2001) elucida, então, que há diferenças linguísticas entre o texto de partida e o texto de chegada, mostrando que não há "neutralidade" ou "literalidade", mas uma leitura de sua versão original (ARROJO, 2003).

Sendo assim, a análise mostra que $39,31 \%$ das modificações presentes representam mudanças semânticas, enquanto $17,11 \%$ indicam mais informação na tradução, juntamente com 13,68\% de mais informação no original. Menos informação no original e na tradução e mudança na avaliatividade aparecem com $8,55 \%$ das diferenças (somando 17,1\%), as expressões idiomáticas representam $6 \%$ das variações juntamente com $6 \%$ das tipologias de língua e $0,8 \%$ de mudança no tema. O que se sugere, então, é que essas modificações mostram o envolvimento do tradutor em língua portuguesa na apropriação do texto de partida, corroborando com Bohunovsky (2001), ou seja, de que a tradução possuiu um tradutor que é um sujeito inserido dentro de um contexto cultural, ideológico, político e psicológico.

Além disso, segundo Fillmore (1988), a visão semântica deve ser colocada dentro de um enquadre cognitivo, sendo as palavras entendidas no contexto estrutural de experiência, crença ou prática, constituindo um pré-requisito para o entendimento de seu significado. Sendo o tradutor responsável por escolhas lexicogramaticais que refletem a ideologia, a subjetividade e a visão de um texto e do que ele significa. Arrojo (1993), diz que o tradutor se torna "visível", ou seja, aquele que se coloca no lugar, tempo e espaço do autor, sem violentar a sintaxe e a fluidez da língua.

Outras diferenças observadas tratam das tipologias de língua e enquadres de verbo $X$ enquadres satélites cada um deles com $6,5 \%$, somando um total de $13 \%$ de modificações que representam escolhas lexicogramaticais diversas dentro de um mesmo referente, sendo necessário critérios linguísticos, pragmáticos e cognitivos, Halliday (1970) afirma que examinar a estrutura linguística em si não é suficiente para explicar a organização de um texto, devendo-se levar em conta, também, o uso da língua, momento em que as escolhas realizadas pelo tradutor são importantes pois 
elas se fazem em detrimento de outras que poderiam ter sido feitas e não foram e tendo, um sentido, criado por essas escolhas.

A análise da tradução em português mostra exatamente esse fato: as escolhas lexicogramaticais feitas pelo tradutor impossibilita, por conta de questões socioculturais, um texto de chegada fiel ao texto de partida. $O$ tradutor, então, movido por crenças e valores de sua cultura, modifica-o, tendo como base as expectativas do leitor brasileiro. Além disso, a análise sistêmico-funcional revela que há uma ideologia marcada, respondendo a aspectos culturais.

\section{REFERÊNCIAS}

ARROJO, R. (Org.). O signo desconstruído: implicações para a tradução, a leitura e o ensino. Campinas: Pontes, 2003.

. Tradução, desconstrução e psicanálise. Rio de Janeiro: Imago, 1993.

BASSNETT, S. Translation Studies. Shanghai: Shanghai Foreign Language Education, 2004.

BELL, R. T. Translation and Translating: theory and practice. Lodnres: Routledge, 1991.

BOHUNOVSKY, R. A (im)possibilidade da "invisibilidade" do tradutor e da "fidelidade": por um diálogo entre a teoria e a prática de tradução. Cadernos de tradução, v. 2, 2001, p. 51-62.

CATFORD, J. C. A linguistic theory of translation. Oxford: Oxford University Press, 1965.

FIGUEIREDO, G. P. The flow of information in Brian Aldiss' supertoys into Brazilian Portuguese. 2006. Disponível em: http://www.pucsp.br/isfc/proceedings/Artigos\% 20pdf/05tr_figueredo_117a154.pdf. Acesso em: 23 nov. 2015.

FILLMORE, C. J.; ATKINS, B. T. Towards a frame-based lexicon: the case of RISK. In: LEHRER, A.; KITTAY, E. (org.) Frames, Fields, and Contrasts. Londres: Erlbaum, 1992.

. The Mechanisms of "Construction Grammar": Proceedings of the Fourteenth Annual Meeting of the Berkeley. Linguistics Society, 1988, p. 35-55.

GOUVEIA, C. A. M.; BÁRBARA, L. Marked or Unmarked, that is not the question. The question is: where's the theme? Ilha do Desterro, v. 46, 2004, p.155-177.

HALLIDAY, M. A. K.; MATTHIESSEN, C. M. I. M. An introduction to Functional Grammar. Londres: Arnolds, 2004. 
. An introduction to Functional Grammar. Londres: Arnolds, 1994.

. Language structure and language function. In: LYONS, J. (org.) New Horizons in Linguistics, v. 3, 1970, p. 140-165.

HOLLOWAY, I. Basic concepts for qualitative research. Oxford: Blackwell Sciente, 1997.

HUANG. G. W. Linguistic explorations in translation studies. Shangai: Shanghai Foreign Language Education Press, 2006.

LI, F. G. Interpersonal meaning and equivalence in translation: A Functional Linguistic Analysis of "Shu Dao Nan" and its English versions. Nanchang: Jiangxi People's Publishing Press, 2007.

MANDELBAUM, D. G. The teaching of Anthropology. Berkeley: University of California Press, 1958.

MARTIN, J. R.; WHITE, P. The language of evaluation: appraisal in English. Nova York: Palgrave, 2005.

. Beyond exchange: APPRAISAL System in English. In: HUNSTON, S. H.; THOMPSON, G. Evaluation in Text - Authorial Stance and the Construction of Discourse. Oxford: Oxford University Press, 2000.

MING, L. Systemic Functional Linguistic approach to translation studies. US-China Foreign Language, 5.8, 2007, p. 74-85.

NIDA, E. A. Contexts in translations. Amsterdam: John Benjamins Publishing Company, 2001.

NINOMIYA, S. R. L. Estruturação temática na tradução de textos literários da língua japonesa para a língua portuguesa: Um enfoque sistêmico-funcional. Tese de Doutorado - Pontifícia Universidade Católica de São Paulo, Programa de PósGraduação em Linguística Aplicada e Estudos da Linguagem, 2012.

ROUDANÉ, M. C. (org.) The Cambridge companion to Tennessee Williams. Cambridge: Cambridge University Press, 2009.

SLOBIN, D. I. Two ways to travel: verbs of motion in English and Spanish. In: MASAYOSHI, S.; THOMPSOM, S. A. Grammatical constructions: their forms and meaning. Oxford: Clarendon Press, 1996.

. Psicolinguística. São Paulo: Companhia Editora Nacional e EDUSP, 1980.

TALMY, L. Path to realization: a typology of event conflation. In: Proceeding of the Seventeenth Annual Meeting of the Berkely Linguistics Society, 1991, p. 480-519. 
. Lexicalization patterns: Semantic Structure in lexical forma. In: SHOPEN, I. Language Typology and Syntactic Description. Londres: Cambrigde University Press, 1985.

WHORF, B. L. Language, thought and culture: selected writings of Benjamin Lee Whorf. New York, NY: Wiley, 1956.

ZHANG, Y.; HUANG, G. A text linguistic approach to translation studies. Chinese Translator Journal, v. 2, 2003, p. 145-153. 